\title{
(110)-Exposed Gold Nanocoral Electrode as Low Onset Potential Selective Glucose Sensor
}

\author{
Ta-Ming Cheng, ${ }^{\dagger}$ Ting-Kai Huang, ${ }^{\dagger}$ Huang-Kai Lin, ${ }^{\dagger}$ Sze-Ping Tung, ${ }^{\dagger}$ Yu-Liang Chen ${ }^{\dagger}$ \\ Chi-Young Lee, ${ }^{\ddagger}$ and Hsin-Tien Chiu* ${ }^{*}$
}

Department of Applied Chemistry, National Chiao Tung University, Hsinchu, Taiwan, 30050, R. O. C, Department of Materials Science and Engineering and Center for Nanotechnology, Materials Science, and Microsystems, National Tsing Hua University, Hsinchu, Taiwan, 30043, R. O. C

\begin{abstract}
A straightforward electrochemical deposition process was developed to grow gold nanostructures, including nanocoral, nanothorn, branched belt, and nanoparticle, on carbon electrodes by reducing $\mathrm{HAuCl}_{4}$ under constant potentials in mixtures containing $\mathrm{CTAC}$ and/or $\mathrm{NaNO}_{3}$. Among the nanostructures, the quasi-one-dimensional nanocoral electrode showed the highest surface area. Because of this, it provided excellent electrochemical performances in cyclic voltammetric (CV) studies for kinetic-controlled enzymefree glucose oxidation reactions. In amperometric studies carried out at $0.200 \mathrm{~V}$ in PBS (pH 7.40, 0.100 M), the nanocoral electrode showed the highest anodic current response. It also offered the greatest sensitivity, $22.6 \mu \mathrm{AmM}^{-1} \mathrm{~cm}^{-2}$, an extended linear range, $5.00 \times 10^{-2} \mathrm{mM}$ to $3.00 \times 10^{1} \mathrm{mM}$, and a low detection limit, $1.00 \times 10^{1} \mu \mathrm{m}$ among the electrodes investigated in this study. In addition, the glucose oxidation by the nanocoral electrode started at $-0.280 \mathrm{~V}$, more negative than the one of using a commercial Au electrode as the working electrode. This is attributed to the presence of exposed Au (110) surfaces on the electrode. The feature was applied to oxidize glucose selectively in the presence of ascorbic acid (AA) and uric acid (UA), common interferences found in physiological analytes. With an applied voltage at $-0.100 \mathrm{~V}$, the AA oxidation (started at $-0.080 \mathrm{~V}$ ) can be avoided while the glucose oxidation still provides a significant response.
\end{abstract}

KEYWORDS: Au nanostrucre • Au (110) plane $\bullet$ selective oxidation $\bullet$ electrochemical glucose sensor

\section{INTRODUCTION}

E ectrocatalytic glucose oxidation is an important research topic in several fields, such as employing glucose in ecologically friendly bio-fuel cells for next generation energy source and sensing glucose in blood for medical applications $(1,2)$. Owning increasing number of people suffering from diabetes recently, many scientists have paid a great deal of attention to the improvement of glucose sensors for blood sugar levels. Clark and Lyons reported the first glucose sensor based on an electrode modified with enzymes in 1962 (3). Glucose oxidase (GOD) has been a common enzyme for glucose oxidation in the presence of oxygen (4). It can catalyze glucose to gluconolactone and produce $\mathrm{H}_{2} \mathrm{O}_{2}$ as a byproduct. Glucose concentration can be estimated from the electrochemical response of the $\mathrm{H}_{2} \mathrm{O}_{2}$ concentration (5-10). In addition, this type of sensors have shown high selectivity to glucose in the analyte. Although these biosensors are widely used, their practical applications are limited by many problems. They suffer from intrinsic instability, complicated immobilization processes in fabrications, and oxygen concentrations in the environment $(4,11)$. Thus, sensors based on direct oxidation of glucose without using enzymes have been expected to avoid such problems.

* Corresponding author. E-mail: htchiu@faculty.nctu.edu.tw (H.-T.C.).

Received for review May 17, 2010 and accepted August 30, 2010

† National Chiao Tung University.

* National Tsing Hua University.

DOI: $10.1021 / \mathrm{am} 100432 \mathrm{a}$

2010 American Chemical Society
There have been many reports related to applying $\mathrm{Cu}$, Pt, and $\mathrm{Au}$ metals as the potential electrochemical electrodes $(12-18)$. For $\mathrm{Cu}$ electrodes, an alkaline solution environment is frequently required for the experiments (18). Although Pt electrodes show high catalytic properties in neutral buffers, they are easily poisoned by intermediates and products generated in the experimental processes so that their intrinsic activities are suppressed (19). Although Au is more stable toward oxidation and poisoning during the experiments, high overpotential and poor sensitivity are always serious challenges for applying $\mathrm{Au}$ as an effective glucose sensor to oxidize glucose (20). Because of the high potential, interfering molecules in the analyte, such as ascorbic acid (AA), are easily oxidized. Consequently, signals from glucose and AA cannot be discriminated easily. Some strategies may be applied to solve this drawback in selectivity. From early research, it is well-known that electrodes with increased surface areas can provide improved performances for kinetically controlled reactions, such as glucose oxidation. On the other hand, it influences diffusion-controlled reactions, for example, AA oxidation, only slightly. Thus, fabricating electrodes with high surface areas is a promising method to increase electrochemical response of glucose but not the one of AA (15). Immobilization of metal nanoaprticles on supporting material such as carbon nanotubes and conductive molecules are frequently used to increase the surface areas $(21,22)$. In addition, hard templates are commonly employed to grow tubelike and porous metal electrodes (23-25). But these methods require complicated 
processing steps. Hence, a template-free method may simplify the fabrication of high surface area electrode signifcantly (26).

In addition to surface areas, chemical reaction kinetics is highly influenced by the nature of the electrode materials. For example, in a recent study, a Pt/Pd composite electrode was used to achieve a glucose oxidation voltage more negative than the one used for AA oxidation (27). Also, several studies show that surface reactions are strongly dependent on crystalline orientations $(28,29)$. This is because different crystal surfaces provide different adsorption sites for reactants, intermediates, and products. For instance, in glucose oxidation, the oxidative currents generated from $\mathrm{Au}$ (111) and $\mathrm{Au}(100)$ planes were higher than the one produced from Au (110) plane. On the other hand, the onset potential observed for the glucose oxidation on $\mathrm{Au}$ (110) was much lower than the ones found for that on $\mathrm{Au}$ (111) and Au (100) (28). Therefore, we anticipate that by oxidizing glucose on $\mathrm{Au}(110)$ at a low potential, interfering signals from the oxidations of other molecules may be avoided. As a result, fabrication of a high-surface-area Au electrode with exposed (110) planes as an enzyme-free glucose sensor appears to be an interesting challenge.

Previously, we reported the growths of several onedimensional nanostructured metals, including $\mathrm{Cu}$ and $\mathrm{Ag}$ nanobelts, $\mathrm{Au}$ nanowires and $\mathrm{Cu}$ nanorods, directly on substrates via simple galvanic reductions $(30-32)$. The morphologies of the as-grown products were highly influenced by the growth conditions, including the surfactant and the anion concentrations, and the reaction temperatures. In this study, we deposit Au nanostructures on commercial carbon screen printed electrodes via a simple electrodeposition route. Using this method, the applied currents can be quantified. Therefore, the amounts of Au deposited on the substrates can be estimated. We are able to fabricate several Au electrodes with different morphologies, including nanocoral, branched belt, nanothorn, and nanoparticle. Among them, the nanocoral electrode not only provides high surface areas but also $\mathrm{Au}$ (110)-like properties toward glucose oxidation. In phosphate buffer solutions (PBS), it demonstrates a great sensitivity, an extended linear range, and selectivity for glucose oxidation. Our discoveries are discussed below.

\section{EXPERIMENTAL SECTION}

Reagents. Gold chloride trihydrate (Aldrich), cetyltrimethylammonium chloride (CTAC, Taiwan surfactant), sodium nitrate (Aldrich), sodium phosphate dibasic dihydrate (Aldrich), sodium phosphate monobasic monohydrate (JT-Baker), D-(+)-glucose (Aldrich), L-ascorbic acid (AA, Aldrich), and uric acid (UA, Aldrich) were used without further purification.

\section{Preparation of Electrodes.}

Nanocoral Electrode. A process similar to the fabrication of one-dimensional Au nanowires was employed here (28). When a CTAC solution $\left(8.90 \times 10^{1} \mathrm{mM}, 0.500 \mathrm{~mL}\right)$ was added to a $\mathrm{HAuCl}_{4}$ solution $\left(5.00 \times 10^{1} \mathrm{mM}, 0.500 \mathrm{~mL}\right)$, the mixture turned from transparent yellow to a suspension of yellow colloids. Then, $\mathrm{NaNO}_{3}\left(1.00 \times 10^{2} \mathrm{mM}, 1.00 \mathrm{~mL}\right)$ and deionized water $(3.00 \mathrm{~mL})$ were assed so that the final suspension contained $5.00 \mathrm{mM} \mathrm{HAuCl}_{4}, 8.90 \mathrm{mM} \mathrm{CTAC}$, and $2.00 \times 10^{1} \mathrm{mM} \mathrm{NaNO}_{3}$. After this mixture was sonicated for $5 \mathrm{~min}$, it was placed in a water bath at $290 \mathrm{~K}$. Electrochemical reduction was performed using a two-electrode electrochemical cell composed of a DC power supply and two carbon electrodes. The cathode was a carbon screen printed electrode, purchased from Zensor R\&D with a geometric area of $0.196 \mathrm{~cm}^{2}$. The anode was fabricated by painting carbon paste on a transparent projection slide and dried at $343 \mathrm{~K}$ on a hot plate under air. Prior to the electrochemical process, the electrodes were rinsed by deionized water and dried by a stream of $\mathrm{N}_{2}$ gas. After the electrodes were immersed into the colloidal suspension, a voltage fixed at 1.80 $\mathrm{V}$ was supplied at $290 \mathrm{~K}$ for $18 \mathrm{~h}$. The total charge supplied to the cell was quantified to be $0.20 \mathrm{C}$. Formation of a dark-red surface on the screen printed carbon electrode (the cathode) was observed (total Au deposited: $0.69 \mu \mathrm{mol}, 140 \mu \mathrm{g}$ ). Finally, the as prepared electrode was rinsed by using deionized water and stored under air before further use.

Other Electrodes. Procedures employing growth parameters varied from the ones discussed above were employed for the preparation of other electrodes with different morphologies. All reactions were performed at $290 \mathrm{~K}$ with a total supplied charge of $0.20 \mathrm{C}$. Branched belt electrode was fabricated by using an electrolyte containing $\mathrm{HAuCl}_{4}(5.00 \mathrm{mM}), \mathrm{CTAC}(8.90 \mathrm{mM})$, and $\mathrm{NaNO}_{3}\left(2.00 \times 10^{1} \mathrm{mM}\right)$ as the electrolyte at an applied voltage $1.60 \mathrm{~V}$ in $24 \mathrm{~h}$. For Au nanothorn electrode, $\mathrm{HAuCl}_{4}(5.00 \mathrm{mM})$ mixed with $\mathrm{NaNO}_{3}\left(2.00 \times 10^{1} \mathrm{mM}\right)$ was reduced at $1.80 \mathrm{~V}$. Because the electrolyte did not contain CTAC, the reaction was completed after $25 \mathrm{~min}$. The third type of electrode, nanoparticle electrode, was grown at $1.80 \mathrm{~V}$ using an electrolyte composed of $\mathrm{HAuCl}_{4}(5.00 \mathrm{mM})$ and CTAC $(8.90 \mathrm{mM})$. The overall reduction time was $20 \mathrm{~h}$. A summary of the electrochemical reaction conditions is shown in Table $\mathrm{S} 1$ in the Supporting Information.

Electrochemical properties of the electrodes prepared in this study were compared to the flat Au electrodes (geometric area $0.196 \mathrm{~cm}^{2}$ ) purchased from Zensor R\&D.

Instrumentation. The electrodes fabricated in this study were characterized by scanning electron microscopy (SEM, JEOL JSM-7410F at $15 \mathrm{kV}$ ), transmission electron microscopy (TEM, JEOL JEM-4000EX), electron diffraction (ED, using LaB 6 as the electron source, accelerated at $400 \mathrm{keV}$ ), and X-ray diffraction, (XRD, Bruker AXS D8 Advance). Cyclic voltammetric $(\mathrm{CV})$ and amperometric experiments were carried out on a $\mathrm{CHI}$ 6081C (CH Instruments) electrochemical analyzer. A threeelectrode system was employed for the measurements. It contained a working electrode, which is an Au electrode fabricated in this study, a counter electrode composed of a Pt wire, and an $\mathrm{Ag} / \mathrm{AgCl}$ (in $3.00 \mathrm{M} \mathrm{KCl}$ ) reference electrode, with a potential of $0.200 \mathrm{~V}$ vs. standard hydrogen electrodes (SHE).

\section{RESULTS AND DISCUSSION}

Preparation and Characterization of Au Nanostructures. A process similar to the fabrication of onedimensional Au nanowires was employed to fabricate the nanostructured Au electrodes (31). In general, electrochemical reduction of an electrolyte containing $\mathrm{HAuCl}_{4}$ mixed with CTAC and/or $\mathrm{NaNO}_{3}$ was carried out using a two-electrode cell system composed of carbon electrodes. A fixed DC voltage was applied for a period of a time so that a total charge of $0.20 \mathrm{C}$ was supplied to grow $140 \mu \mathrm{g}$ of $\mathrm{Au}$ on the cathode. Four types of electrodes, composed of nanocoral, branched belt, nanothorn, and nanoparticle, were fabricated. A summary of the reaction conditions is listed in Table $\mathrm{S} 1$ in the Supporting Information. Electrochemical properties of the fabricated electrodes were compared to the flat $\mathrm{Au}$ electrodes supplied by Zensor R\&D. Because the nanocoral 


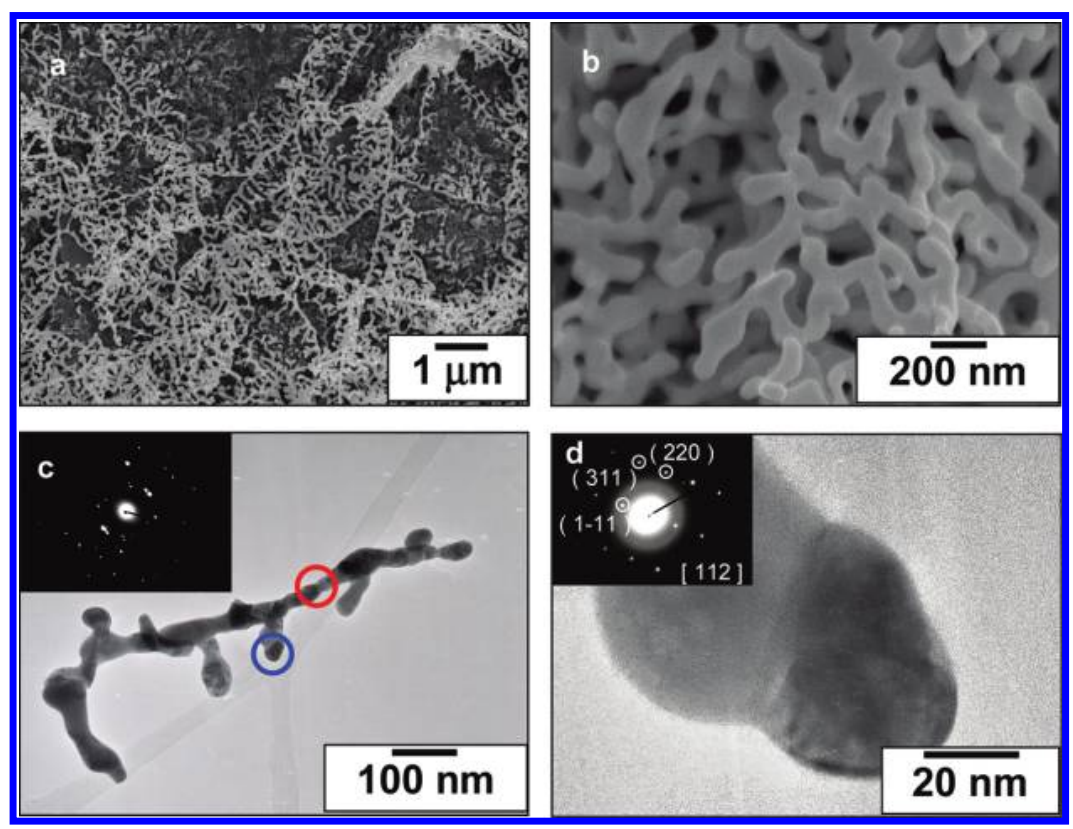

FIGURE 1. (a) Low- and (b) high-magnification SEM images of nanocoral electrodes. (c) Low-magnification TEM image (inset, SAED from the red circle) and (d) high-magnification TEM image from the blue circle in c (inset, SAED).

showed the best performance among them, its characterization will be discussed in detail below.

As shown in Figure 1a, a low-magnification SEM image displays that the surface of an as-deposited electrode is densely covered by coral-like quasi-one-dimensional nanostructures. The high magnification image shown in Figure $1 \mathrm{~b}$ suggests that the widths of the coral structures are about 100-200 nm. In Figure 1c, a low-magnification TEM image of a nanocoral, with a major stem and several branches, is presented. Each branch has a width about $100 \mathrm{~nm}$. This agrees well with the SEM result. The clear contrasts from different areas of this nanostructure indicate that the nancoral is composed of many grains. This is confirmed by the selected area electron diffraction (SAED) pattern (inset, Figure 1c) from the red circled area shown in Figure 1c. The pattern suggests the presence of a polycrystalline structure. A high magnification image from the blue circle is shown in Figure $1 \mathrm{~d}$. The SAED pattern in the inset shows the dot pattern of a single crystal. From both SAED patterns, the $d$ spacings are estimated. They are consistent with the reflections from corresponding Au planes. In addition, the crystallographic zone axis is determined to be [112]. From the electrochemical characterizations discussed below, we discover that the surface structure of the nanocoral resembles that of the branched belt, with highly exposed $\mathrm{Au}(110)$ planes.

XRD were used to analyze the crystal structure of the electrodes prepared in this study also. In the Supporting Information, Figure S1 showed the XRD pattern of a nanocoral electrode. The peaks at $2 \theta=38.1^{\circ}, 44.3^{\circ}, 64.5^{\circ}$, $77.5^{\circ}$, and 81.7 were assigned to $\mathrm{Au}$ (111), (200), (220), (311), and (222) reflections, respectively (JCPDF 89-3697). In addition, the peaks from the carbon electrode substrate were observed at $2 \theta=46.3,54.4$, and $86.8^{\circ}$. The XRD result confirmed that face-centered-cubic (FCC) $\mathrm{Au}$ is a major component on the electrode.
Characterization data of other electrodes are shown in the Supporting Information. In Figure S2, SEM images of nanoparticle, nanothorn, and branched belt electrodes were presented. They all showed XRD patterns similar to the one displayed in Figure S1 in the Supporting Information. A sample from the branched belt electrode was further investigated by TEM, as shown in Figure S3 in the Supporting Information. The image in Figure S3a in the Supporting Information displayed many ripplelike patterns. This feature, originated from the strains of bending of thin samples, was frequently observed in TEM studies for nanobelts (30). In addition, a boundary region near the middle of the sample was observed. The SAED of this region, from the red circle in Figure S3a, showed a superposition of two identical patterns with a twisted angle of $70.53^{\circ}$. Each pattern was composed of dots from (111) and (200) planes while [110] was determined to be the zone axis. As a consequence, we conclude that the branched belt surface was an exposed Au (110) plane. This is further confirmed by the electrochemical characterization of the electrode discussed below.

Surface Area Determination. Because all of the electrodes grown in this study contained the same amount of $\mathrm{Au}$, their real surface areas (RSA) were characterized by $\mathrm{CV}$ in a $0.5 \mathrm{M} \mathrm{H}_{2} \mathrm{SO}_{4}$ solution. The corresponding $\mathrm{CV}$ diagrams are shown in Figure 2. The anodic responses starting at $1.10 \mathrm{~V}$ are due to the formation of Au oxides (33). Subsequently, in the negative potential scan, they are reduced at about $0.900 \mathrm{~V}$. By integrating the charge consumed for reducing the Au oxides formed in the positive scan, the RSAs of the electrodes are calculated by assuming that the reduction of a monolayer of Au oxides require $386 \mu \mathrm{C} \mathrm{cm}^{-2}$ (33). The results are listed in Table 1. Among all samples, the nanocoral electrode shows the highest RSA, $1.81 \mathrm{~cm}^{2}$, whereas the commercial Au electrode has the lowest value, $0.155 \mathrm{~cm}^{2}$. We suggest that the morphology and the exposed 


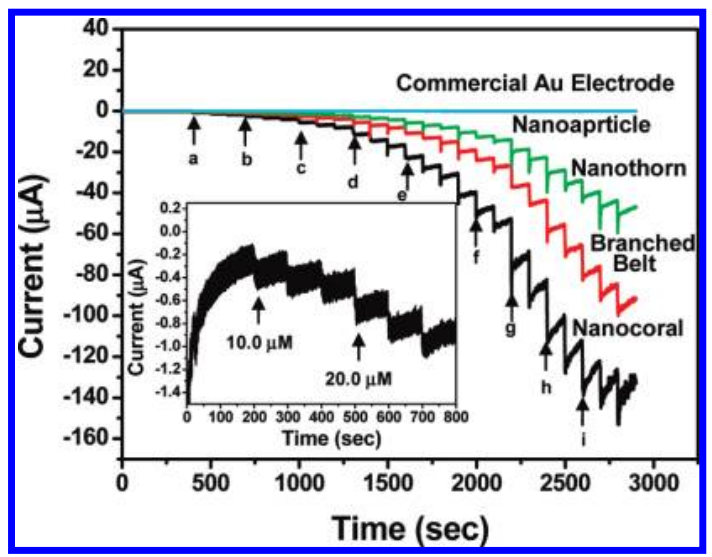

FIGURE 4. Amperometric current responses at $0.200 \mathrm{~V}$. Glucose was successively injected ((a) $5.00 \times 10^{-2} \mathrm{mM}$, (b) $1.00 \times 10^{-1} \mathrm{mM}$, (c) $2.00 \times 10^{-1} \mathrm{mM}$, (d) $5.00 \times 10^{-1} \mathrm{mM}$, (e) $1.00 \mathrm{mM}$, (f) $2.00 \mathrm{mM}$, (g) $5.00 \mathrm{mM}$, (h) $8.00 \mathrm{mM}$, and (i) $10.00 \mathrm{mM}$ ) into stirred PBS (pH 7.40, $0.100 \mathrm{M})$. The working electrodes are nanocoral (black), branched belt (red), and nanothorn (light green). Responses from nanoparticle (blue) and commercial (light blue) Au electrodes are too weak to be seen clearly. Inset shows the lowest concentration to be detected at $1.00 \times 10^{1} \mu \mathrm{M}$.

ing that their (110) surfaces were highly exposed too. The nanoparticle electrode showed the lowest current response. This is attributed to its relatively low surface area and poor adsorption of hydroxides from the solution. We discovered that while the RSA of the nanocoral electrode is about twelve times higher than that of the commercial electrode (Table 1 ), the anodic current of the nanocoral is only twice of the commercial one (Figure 3). This is another support that the nanocoral electrode has highly exposed Au (110) surfaces. According to the literature, with the same surface areas, the Au (110) surface provided a smaller anodic current than did the Au (111) and the Au (100) (28).

Amperometric Studies. In theory, the amperometric current should respond linearly to the glucose concentration at a fixed voltage. Thus, the catalytic glucose oxidation capabilities of the electrodes can be evaluated. In order to fit the physiology condition, we employed a PBS solution ( $\mathrm{pH}$ $7.40,0.100 \mathrm{M}$ ) as our electrolyte. Also, to prevent oxidation of the Au electrode surfaces that may suppress glucose oxidation during the amperometric tests and to avoid strong background currents, a constant potential at $0.200 \mathrm{~V}$ was selected for the studies. Glucose with known concentration was then injected sequentially into the electrolyte at an interval of $100 \mathrm{~s}$. The results are shown in Figure 4. It indicates that the nanocoral electrode performs the best. A rapid increase in the anodic current can be observed after each addition of glucose to the stirred solution. The inset in Figure 4 shows that the detection limit is $1.00 \times 10^{1} \mu \mathrm{M}$ of glucose. The branched belt and the nanothorn electrodes respond less to the glucose additions. On the other hand, the nanoparticle and the commercial Au electrodes performed poorly, as shown in Figure S5 in the Supporting Information. This can be reasoned by their low surface areas. In Figure 5, the calibration curves derived from the data shown in Figure 4 are shown. An extended linear range from $5.00 \times 10^{-2} \mathrm{mM}$ to $3.00 \times 10^{1} \mathrm{mM}$ is shown for the nanocoral electrode. The result suggests that the elec-
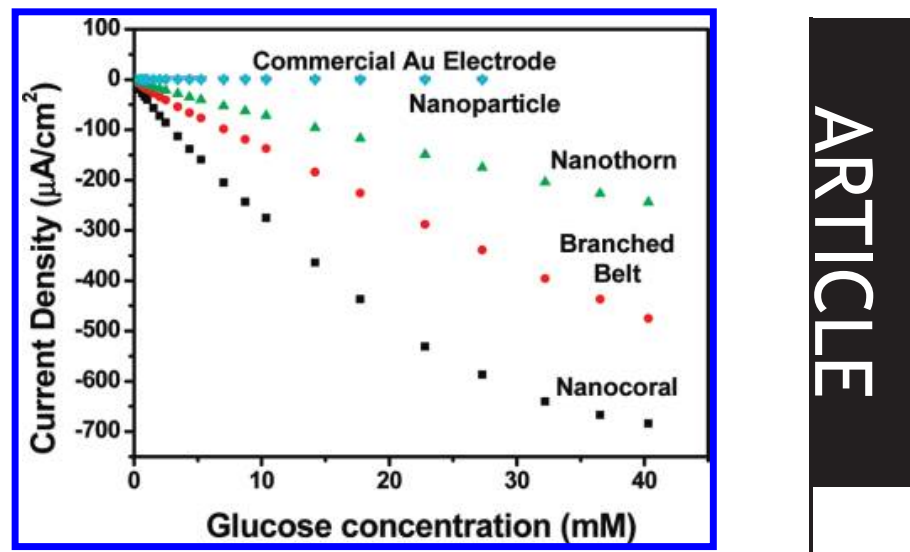

FIGURE 5. Calibration curves of amperometric tests shown in Figure 4. The working electrodes are nanocoral (black), branched belt (red), and nanothorn (light green). Responses of nanoparticle (blue) and commercial (light blue) $\mathrm{Au}$ electrodes are too weak to be seen clearly.

trode is potentially suitable for the physiological glucose concentration (3-8 mM) (34). The nanocoral electrode also possesses the highest calculated sensitivity among all electrodes investigated in this study, $22.6 \mu \mathrm{A} \mathrm{cm} \mathrm{cm}^{-2} \mathrm{mM}^{-1}$. The linear range and the sensitivity of the other electrodes are summarized in Table 1. For comparison, we have listed some results from other $\mathrm{Au}$ and $\mathrm{Pt}$ glucose sensors in Table 2.

Selectivity of Nanocoral Electrode. In real physiological samples, AA and UA with concentrations about onetenth of the glucose value normally coexist with it. Their presence may interfere with the electrochemical detection of glucose. To investigate whether the nanocoral electrode fabricated in this study may selectively detect glucose in the presence of AA and UA, we performed the following investigations. The CV scans of the electrode in $3.00 \mathrm{mM}$ glucose, $3.00 \mathrm{mM} \mathrm{AA}$, and $3.00 \mathrm{mM}$ UA are shown in Figure 6a. There is no apparent response from UA. On the other hand, AA is easily oxidized above $-0.080 \mathrm{~V}$, the onset potential, and shows a great response that overwhelms the signal generated from the glucose oxidation. Because of the exposed Au (110) surface of the nanocoral electrode, the onset potential for the glucose oxidation is observed at $-0.280 \mathrm{~V}$, which is much lower than the one recorded for the AA oxidation. Thus, a relatively strong anodic response from the glucose oxidation can still be seen between -0.280 and $-0.080 \mathrm{~V}$ in Figure 6a. The CV scans of the commercial Au electrode are shown in Figure 6b. Because of its smaller surface area, all of the responses are weaker than the ones obtained from the nanocoral electrode. In addition, the anodic response of the glucose oxidation, because of its higher onset potential, is completely surpassed by the AA oxidation signal. The amperometric responses of glucose (10.0 mM) and AA (1.00 $\mathrm{mM}$ ) oxidations in PBS between -0.100 and $0.200 \mathrm{~V}$ were further investigated. The results are shown in Figure 7 . The data of the nanocoral electrode (Figure $7 \mathrm{a}$ ) clearly indicates that the AA oxidation current at $-0.100 \mathrm{~V}$ can be ignored in comparison with the glucose oxidation signal. On the other hand, by using the commercial Au electrode, AA oxidation is predominant within the applied potential range. There is 
Table 2. Summary of Performances of Noble Metal Glucose Sensors electrode applied potential $(\mathrm{V}) \quad$ sensitivity $\left(\mu \mathrm{A} \mathrm{cm}^{-2} \mathrm{mM}^{-1}\right)$

\begin{tabular}{|c|c|c|c|c|c|}
\hline electrode & applied potential (V) & sensitivity $\left(\mu \mathrm{A} \mathrm{cm}^{-2} \mathrm{mM}^{-1}\right)$ & linear range $(\mathrm{mM})$ & detection limit $(\mu \mathrm{M})$ & ref \\
\hline Au nanocoral & $0.200^{a}$ & 22.6 & $0.0500-30.0$ & 10 & this study \\
\hline Au branched belt & $0.200^{a}$ & 11.9 & $0.0500-40.0$ & 10 & this study \\
\hline Au NPs/MPTS & $0.16^{a}$ & 179 & $0-8$ & 0.05 & $(22)$ \\
\hline porous Au & $0.25^{a}$ & 32 & $0-10$ & 2 & (35) \\
\hline macroporous Au & $0.35^{b}$ & 11.8 & $2-10$ & 0.05 & (25) \\
\hline roughened $\mathrm{Au}$ & $0.3^{b}$ & N/A & $0-57.5$ & 0.75 & (26) \\
\hline mesoporous Pt & $0.4^{a}$ & 9.6 & $0-10$ & N/A & $(15)$ \\
\hline Pt nanotube & $0.4^{b}$ & 0.1 & $2-14$ & 1 & (16) \\
\hline nanoporous Pt & $0.4^{a}$ & 291.0 & $0-10$ & N/A & $(17)$ \\
\hline nanoporous $\mathrm{Pt}-\mathrm{Pb}(50 \%)$ Network & $0.4^{a}$ & 10.8 & $1-16$ & N/A & $(27)$ \\
\hline ACCU-CHECK comfort curve ${ }^{c}$ & N/A & N/A & $0.6-33.3$ & 600 & (36) \\
\hline
\end{tabular}

${ }^{a}$ The reference electrode is an $\mathrm{Ag} / \mathrm{AgCl}$ (in $\mathrm{KCl} 3.00 \mathrm{M}$ ) electrode $\left(0.200 \mathrm{~V}\right.$ versus SHE). ${ }^{b}$ The reference electrode is a saturated calomel electrode (SCE) $\left(0.242 \mathrm{~V}\right.$ versus SHE). ${ }^{c}$ The test strip is modified by glucose dehydrogenase. ${ }^{d}$ The working electrode is modified by GOD.

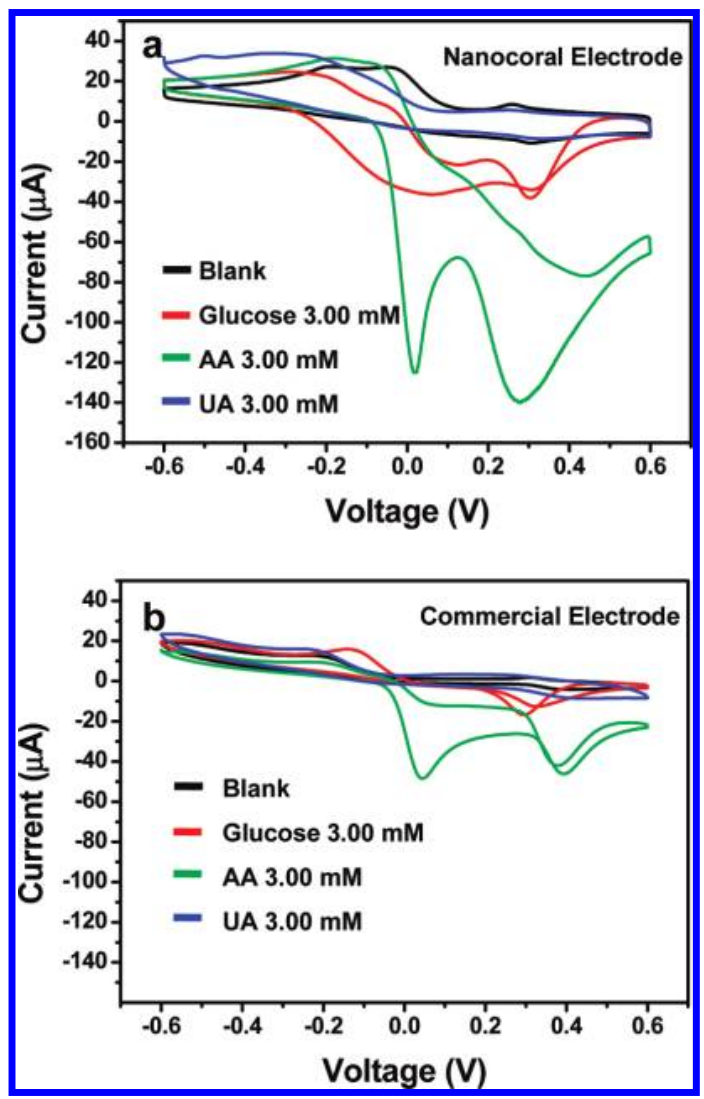

FIGURE 6. Comparison of CV scans. Blank (black), additions of glucose (3.00 mM, red), AA (3.00 mM, light green), and UA (3.00 mM, blue) in PBS ( $\mathrm{pH} 7.49,0.100 \mathrm{M}$ ) to (a) nanocoral and (b) commercial Au electrodes.

no suitable potential to initiate an observable glucose oxidation reaction. As shown in Figure 8, analyses of interferences from AA and UA to glucose oxidation on the nanocoral electrode were performed at $-0.100 \mathrm{~V}$. Injecting UA (1.00 $\mathrm{mM}$ ) to a PBS electrolyte (Figure 8a) does not generate a significant response. A clear signal is then observed after the addition of glucose $(10.0 \mathrm{mM})$. A similar phenomenon is detected in Figure $8 \mathrm{~b}$ for the introduction of AA (1.00 mM)

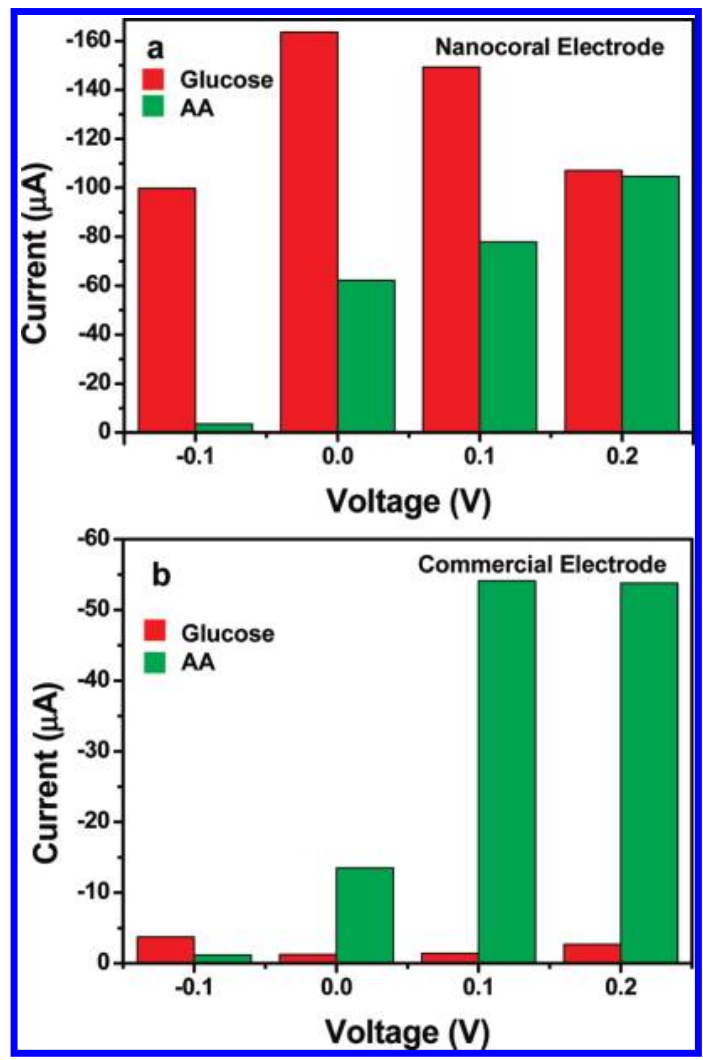

FIGURE 7. Comparison of amperometric signals of glucose $(1.00 \times$ $10^{1} \mathrm{mM}$, red) and AA (1.00 mM, green) on (a) nanocoral and (b) commercial Au electrodes at different applied voltages in PBS (pH $7.40,0.100 \mathrm{M})$.

followed by the addition of glucose. Figure 8c clearly shows that successive addition of AA and UA does not generate anodic signals. Further injection of glucose to the electrode still shows a clear oxidation signal. The glucose oxidation currents generated in the presence of UA (Figure 8a,c) are lower than the one produced without the addition of UA (Figure 8b). We suggest that although UA molecules are not oxidized, they may cap the Au surface sites so that the glucose oxidation ability is decreased. We believe the per- 


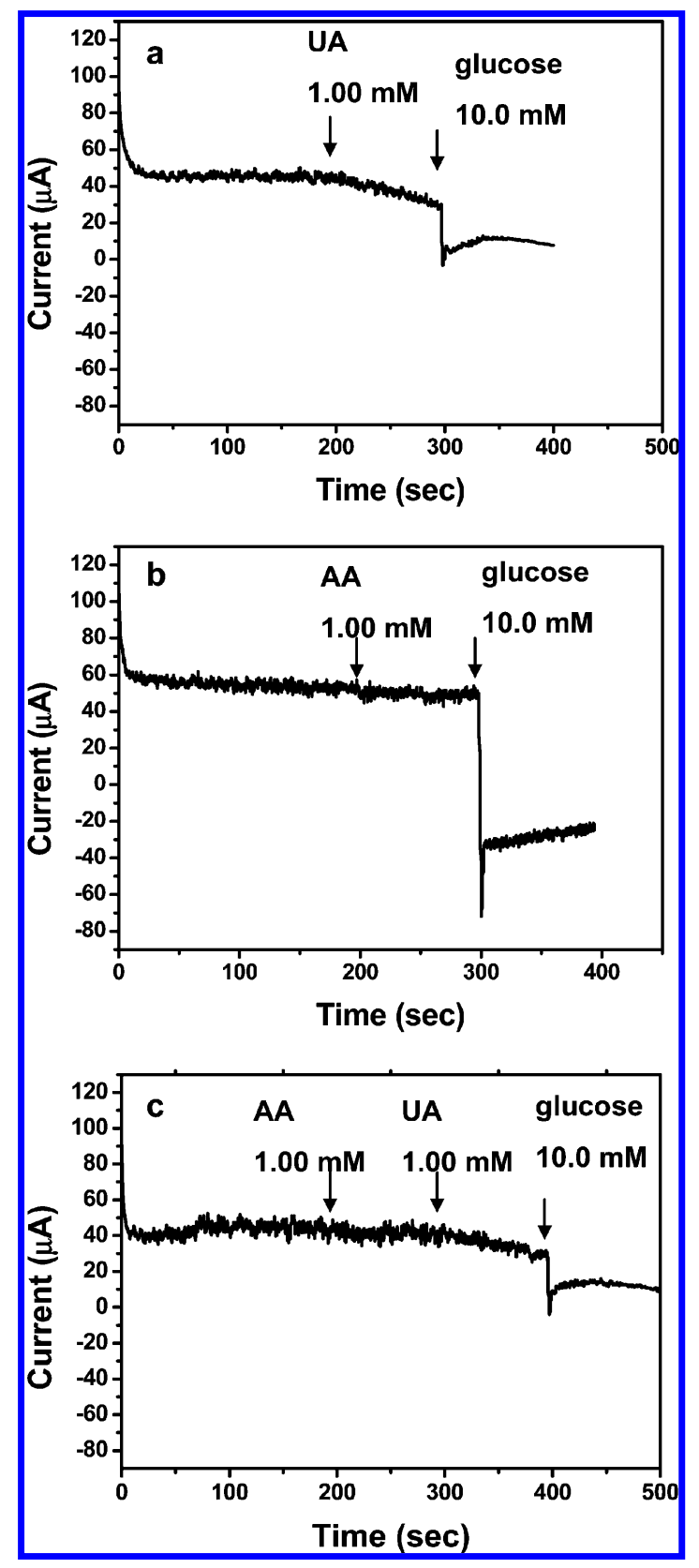

FIGURE 8. Interference analyses by amperometry at $-0.100 \mathrm{~V}$. The injection sequences are (a) UA $(1.00 \mathrm{mM})$ and glucose $\left(1.00 \times 10^{1}\right.$ $\mathrm{mM})$, (b) AA (1.00 mM) and glucose $\left(1.00 \times 10^{1} \mathrm{mM}\right)$, and (c) AA $(1.00 \mathrm{mM})$, UA $(1.00 \mathrm{mM})$ and glucose $\left(1.00 \times 10^{1} \mathrm{mM}\right)$.

formance of the nanocoral electrode can be improved by adjusting the electrode growth condition, the morphology, the real surface area, and the geometric area.

Stability of Nanocoral Electrode. The same nanocoral electrode was used repeatedly to oxidize glucose (1.00 $\left.\times 10^{1} \mathrm{mM}\right)$ at $0.20 \mathrm{~V}$ for eight times. Between each measurement, deionized water was used to rinse the electrode surface and ten CV scan cycles were employed at a potential range from $-1.00 \mathrm{~V}$ to $1.30 \mathrm{~V}$ in PBS ( $\mathrm{pH} 7.40,0.100 \mathrm{M})$. As shown in Figure S6 in the Supporting Information, no obvious anodic current decay can be observed. After these tests, the SEM image of the electrode was displayed in Figure $S 7$ in the Supporting Information. The image indicated that the original nanocoral morphology was maintained. The data suggest that the electrode is stable upon repeated uses and cleanings. It is possible that fresh $\mathrm{Au}(110)$ surface is exposed again after the proper electrochemical process.

Comparison with Enzyme-Based Electrodes. To further evaluate the potential of our nanocoral electrode, we listed the performances of some enzyme-based glucose sensors in Table 2 (36-38). ACCU-CHEK Comfort Curve, a commercial test strip modified with potassium ferricyanide and glucose dehydrogenase on a substrate with supported $\mathrm{Pd}$, has a similar measurement range, $0.6-33.3 \mathrm{mM}$ (34). Its reported detection limit, $0.6 \mathrm{mM}$, is higher than that of our nanocoral electrode. We should be aware that the data of ACCU-CHEK Comfort Curve were taken in real physiological samples instead of PBS solutions. When the commercial strip is used to detect glucose concentration in blood, it has limited tolerance towards the interfering species, such as UA. When the UA concentration exceeds the limitation, it may cause deviation of response to glucose oxidation. Our nanocoral electrode also displays comparable tolerance towards the interfering species. It shows in Figure 8 a discernible signal at $-0.100 \mathrm{~V}$ for $10 \mathrm{mM}$ glucose in the presence of 1 mM UA and $1 \mathrm{mM} \mathrm{AA}$. Our Au nanocoral electrode is further compared with some GOD-based CNT electrodes listed in Table 2. Although their detection limits are comparable, the sensitivity and the linear range of our electrode exceeds the performance of the GOD modified Au NPs/MWCNT/Nafion and Pt NPs/SWCNT electrodes $(37,38)$. Consequently, we anticipate that our Au nanocoral electrode will have a great potential for sensing glucose concentrations in physiological samples. Further investigations are in progress.

\section{CONCLUSION}

In this study, a simple electrochemical deposition method has been developed to grow gold nanostructures on commercial carbon electrodes. Different morphology, including nanocoral, branched belt, nanothorn, and nanoparticle, can be grown successfully. Among the electrodes fabricated, the nanocoral electrode shows the highest real surface area. This is the major reason why it provides the greatest sensitivity toward a kinetic-controlled glucose oxidation. By using the nanocoral electrode, the sensitivity for glucose oxidation is estimated to be $22.6 \mu \mathrm{A} \mathrm{mM}^{-1} \mathrm{~cm}^{-2}$ from $5.00 \times 10^{-2} \mathrm{mM}$ to $3.00 \times 10^{1} \mathrm{mM}$ at an applied potential $0.200 \mathrm{~V}$ in PBS, whereas the detection limit is observed at $1.00 \times 10^{1} \mu \mathrm{m}$. Another important feature of the electrode is that it can oxidize glucose at a more negative on set potential than a common commercial Au electrode does. This is attributed to the presence of exposed $\mathrm{Au}$ (110) planes on the electrode surface. Because of this property, glucose in a mixture of glucose and AA can be selectively oxidized at $-0.100 \mathrm{~V}$. Thus, the interfering signal from AA oxidation can be excluded successfully. When the electrode is operated in a mixture of glucose, AA and UA, it can still provide a meaningful glucose oxidation signal response. We believe the electrochemical performance of the electrode can be improved further by optimizing the growth condition, the morphology, the real surface area, and the geometric area. Moreover, the electrode can be used repeatedly after a 
proper cleaning procedure. All these properties suggest that the nanocoral electrode is a candidate for a promising glucose biosensor.

Acknowledgment. We are grateful for the support from the National Science Council, "Aim for the Top University Plan" of the National Chiao Tung University, and the Ministry of Education of Taiwan, the Republic of China. The authors thank Professor Y.-Z. Hsieh for discussion and help in electrochemical experiments.

Supporting Information Available: Summary of growth conditions of electrodes, XRD, SEM, TEM, ED, CV, and amperometric analyses data (PDF). This material is available free of charge via the Internet at http://pubs.acs.org.

\section{REFERENCES AND NOTES}

(1) Reach, G.; Wilson, G. S. Anal. Chem. 2008, 64, 381 A.

(2) Kendall, K. Nat. Mater. 2002, 1,211

(3) Leland, C. C., Jr.; Champ, L. Ann. N. Y. Acad. Sci. 1962, 102, 29

(4) Wilson, R.; Turner, A. P. F. Biosens. Bioelectron. 1992, 7, 165.

(5) Battaglini, F.; Bartlett, P. N.; Wang, J. H. Anal. Chem. 1999, 72, 502 .

(6) Wilson, G. S.; Hu, Y. Chem. Rev. 2000, 100, 2693.

(7) Heller, A. Acc. Chem. Res. 2002, 23, 128.

(8) Zen, J.-M.; Kumar, A. S.; Chung, C.-R. Anal. Chem. 2003, 75, 2703.

(9) Lawrence, N. S.; Deo, R. P.; Wang, J. Anal. Chem. 2004, 76, 3735.

(10) Mano, N.; Heller, A. Anal. Chem. 2005, 77, 729

(11) Park, S.; Boo, H.; Chung, T. D. Anal. Chim. Acta 2006, 556, 46.

(12) Jia, F.; Yu, C.; Deng, K.; Zhang, L. I. Phys. Chem. C 2007, 111, 8424.

(13) Jia, F.; Yu, C.; Ai, Z.; Zhang, L. Chem. Mater. 2007, 19, 3648.

(14) Song, Y. Y.; Zhang, D.; Gao, W.; Xia, X. H. Chem.-Eur. I. 2005, 11, 2177.

(15) Park, S.; Chung, T. D.; Kim, H. C. Anal. Chem. 2003, 75, 3046.

(16) Yuan, J. H.; Wang, K.; Xia, X. H. Adv. Funct. Mater. 2005, 15, 803

(17) Chou, C. H.; Chen, J. C.; Tai, C. C.; Sun, I. W.; Zen, J. M. Electroanalysis. 2008, 20,771.

(18) Hung, T.-K.; Lin, K.-W.; Tung, S.-P.; Cheng, T.-M.; Chang, I.-C.; Hsieh, Y.-Z.; Lee, C.-Y.; Chiu, H.-T. L.Electroanal. Chem. 2009, 636, 123
(19) Chang, S. C.; Leung, L. W. H.; Weaver, M. J. L. Phys. Chem. 1990, 94, 6013 .

(20) Ernst, S.; Heitbaum, J.; Hamann, C. H. L. Electroanal. Chem. 1979, 100, 173.

(21) Myung, Y.; Jang, D. M.; Cho, Y. J.; Kim, H. S.; Park, J.; Kim, J.-U.; Choi, Y.; Lee, C. J. J. Phvs. Chem. C 2009, 113, 1251.

(22) Bikash Kumar, J.; Raj, C. R. Chem.-Eur.I. 2006, 12, 2702.

(23) Bai, Y.; Yang, W.; Sun, Y.; Sun, C. Sens. Actuators, B 2008, 134, 471

(24) Zhou, Y.-G.; Yang, S.; Qian, Q.-Y.; Xia, X.-H. Electrochem. Commun. 2009, 11, 216

(25) Li, Y.; Song, Y.-Y.; Yang, C.; Xia, X.-H. Electrochem. Commun. 2007, 9, 981

(26) Zhao, W.; Xu, J.-J.; Shi, C.-G.; Chen, H.-Y. Electrochem. Commun. 2006, 8, 773 .

(27) Wang, J.; Thomas, D. F.; Chen, A. Anal. Chem. 2008, 80, $997-$ 1004.

(28) Hsiao, M. W.; Adzic, R. R.; Yeager, E. B. L. Electrochem. Soc. 1996, 143, 759 .

(29) Popovic, K.; Tripkovic, A.; Markovic, N.; Adzic, R. R. L. Electroanal. Chem. 1990, 295, 79.

(30) Huang, T.-K.; Cheng, T.-H.; Yen, M.-Y.; Hsiao, W.-H.; Wang, L.S.; Chen, F.-R.; Kai, J.-J.; Lee, C.-Y.; Chiu, H.-T. Langmuir 2007 , 23, 5722 .

(31) Huang, T.-K.; Chen, Y.-C.; Ko, H.-C.; Huang, H.-W.; Wang, C.-H.; Lin, H.-K.; Chen, F.-R.; Kai, J.-J.; Lee, C.-Y.; Chiu, H.-T. Lanamuir 2008, 24, 5647.

(32) Chang, I.-C.; Huang, T.-K.; Lin, H.-K.; Tzeng, Y.-F.; Peng, C.-W.; Pan, F.-M.; Lee, C.-Y.; Chiu, H.-T. ACS Appl. Mater. Interfaces 2009, 1,1375 .

(33) Trasatti, S.; Petrii, O. A. Pure Appl. Chem. 1991, 63, 711.

(34) Sun, Y. P.; Buck, H.; Mallouk, T. E. Anal. Chem. 2003, 73, 1599

(35) Cho, S.; Kang, C. Electroanal. 2007, 19, 2315.

(36) These electrochemical parameters can be found at the Web site: http://www.poc.roche.com/en_US/pdf/Evaluation_Report001. pdf.

(37) Rakhi, R. B.; Sethupathi, K.; Ramaprabhu, S. I. Phys. Chem. B 2009, 113, 3190

(38) Hrapovic, S.; Liu, Y.; Male, K. B.; Luong, J. H. T. Anal. Chem. 2004, $76,1083$.

AM100432A 